



\section{PREPARING BEES FOR WINTER}

\section{B. Gooderham, Dominion Apiarist}

One of the most important phases of beekeeping in Canada is the preparation of bees for winter. The care given to this work will largely determine the number of living colonies the following spring. Every year a large number of colonies die or become seriously weakened when a little more care and better management would have saved them.

To winter bees successfully the following conditions must be provided:-

1. Each colony must contain a strong force of young bees.

2. Bees must have a plentiful supply of wholesome food.

3. They must be well protected from cold and changeable weather.

The beekeeper is entirely responsible for providing these conditions. To neglect any one of them is to nullify the benefits of the others, and thus to invite disaster.

\section{STRONG COLONIES OF YOUNG BEES}

To ensure plenty of young bees each colony must be headed with a young prolific queen during the early fall months, August and September, because it is the eggs laid during this period that will produce the force of bees that are to live through the winter. Another advantage of having the colonies headed with young queens in the fall is that the queens are still young and vigorous the following spring and thus able to build the colonies up to maximum producing strength in much shorter time than could old and worn-out queens.

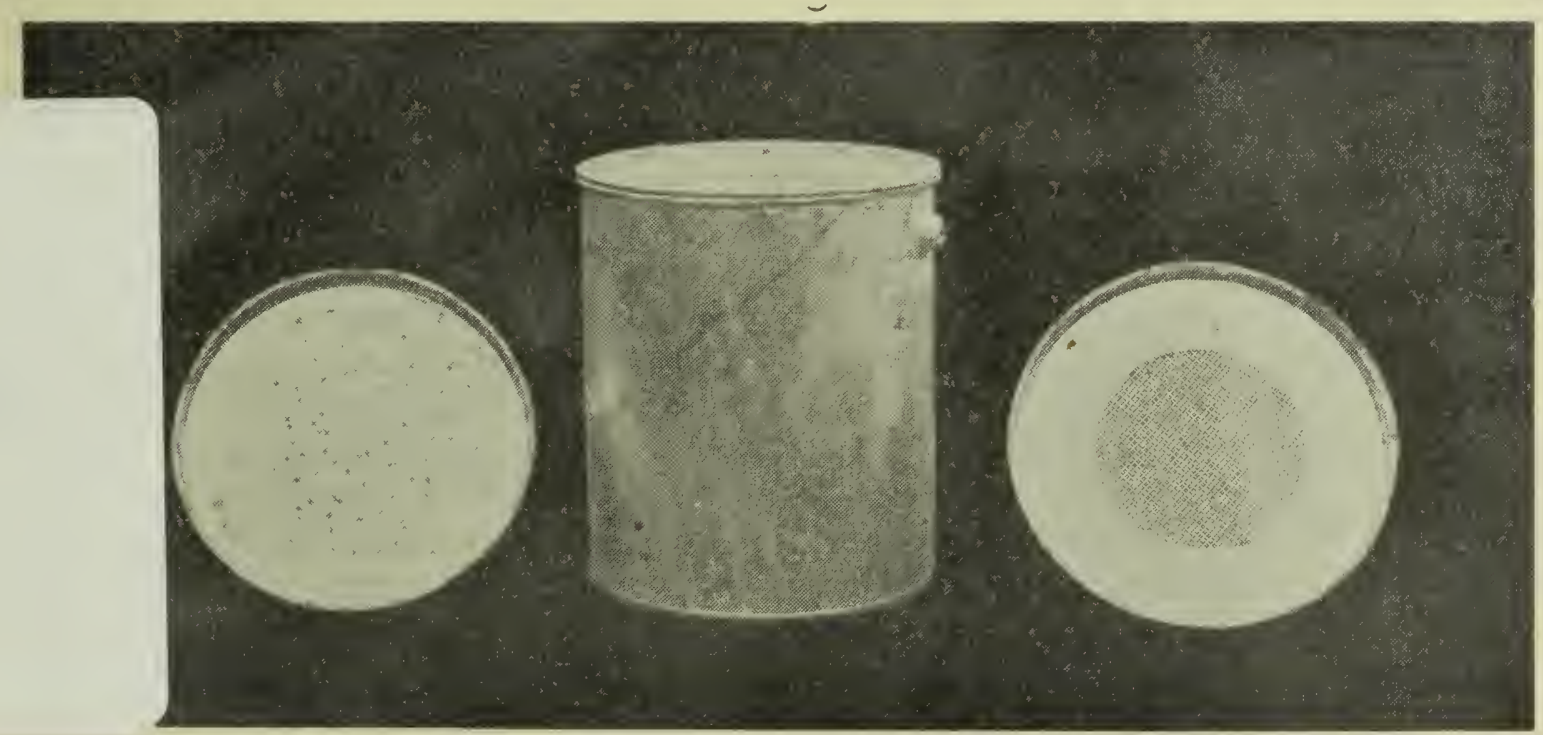

Fig. 1.-Ten-pound honey-pail feeder. (Left) Cover perforated with fine nail. (Right) Cover fitted with perforated zinc. 
Leaving old queens in the colonies during the fall too often results in the following:-

1. Supersedure too late in the fall for the new queens to become mated, thus the colonies will be headed with drone-producing queens in the spring.

2. Old queens may perish during the winter, thus leaving the colonies hopelessly queenless.

3. The queens may suddenly fail during the critical brood rearing period of spring, thus preventing the colonies from building up to producing strength in time for the harvest.

A strong colony is one that has sufficient bees to cover at least eight fullsized Langstroth combs on or about the first of October. A strong force of bees is able to protect itself during the cold weather much better than a weak one. Furthermore, the consumption of food will be proportionately less in the strong colony. The bees must be young because they will live longer than old bees and thus are more likely to survive until the brood rearing is well advanced the following spring.

All colonies that are weak in the fall should be united with others in order to bring them up to the required strength. Alternately two weak colonies may be wintered in one hive with a bee-tight division board between them.

In addition to having young queens, bees must have sufficient stores to feed the maximum amount of brood the queens are able to produce. In many districts the fall honey flow is not sufficient for this purpose, therefore, a supply from the main honey crop must be left with the bees or the latter must be fed syrup. Any shortage of food in the fall will cause a check in brood rearing, thus reducing the possible strength of the colony.

\section{THE FOOD SUPPLY}

The food supply for bees for the winter must be given before cold weather sets in, and this supply must be a liberal one because it is far better to find strong colonies with a surplus of food in the spring than it is to find them dead from starvation. A large number of. colonies die each spring, and a great many more are seriously weakened because their food supply was not quite enough to last them until a new supply was available from the fields. In either case a double loss occurs; first the food supply that has given, and secondly the bees themselves. An extra ten pounds of food given in the fall might have saved both. Every colony should contain at least forty pounds of food when ready for the wirter; any amount in excess of this is an extra insurance against loss. A good rule to follow is to give the bees all they can store.

In most regions and most seasons the feeding may be done any time during the last week of September or the first two weeks of October. If the weather remains fair and warm, then feeding may be done even later than the middle of October, but it is not wise to delay feeding until then for fear cold weather may set in suddenly. Once started the feeding should be completed as rapidly as possible in order to avoid undue disturbance of the bees. During the feeding period every care must be taken not to expose honey or syrup in places within reach of the bees, otherwise robbing will be started.

If the bees are to be wintered on honey alone, only clover or buckwheat honey should be given. Spring- or fall-gathered honey or honey obtained largely from alfalfa is unsafe. If there is any doubt as to the quality of the honey fed back, it is advisable to finish the feeding with sugar syrup. A wellfilled super of capped honey should be saved from the main crop and given back to the bees at feeding time. Do not feed back honey unless it is known to be from colonies free from disease. 
If the food supply is to consist of sugar syrup, only the best white sugar should be used, making this into a solution of two parts sugar to one part water. First bring the water to boiling point and then stir in the required amount of sugar, taking care that the sugar is thoroughly dissolved, otherwise the syrup may re-crystallize in the combs. Heat may be used to hasten the melting of the sugar but care must be taken not to scorch or burn the sugar, as such sugar is fatal to the bees.

The No. 10 honey pail with twenty or thirty fine holes punched in its cover makes an ideal feeder can, although other types are available. First remove the covers from the colonies to be fed and then add an empty super to each colony. Fill the feeder can with warm syrup, place the punched covers on securely and then invert the pails in the empty supers, resting the pails upside down on the top bars of the frames below. One or more pails can be given to each colony at the same time. If honey boards or quilts are used between the colony and the feeder cans, then provision must be made for the bees to get through them to the feeders above. It is best to do the feeding in the evenings after all bee-flight has stopped, or on a dull day, thus reducing the danger of excitement and robbing on the part of the bees.

\section{PROTECTION}

Bees may be wintered in cellars or outside winter cases. If one has a good cellar for the bees, the cost of cases can be avoided, but if no such cellar is available the building of cases is preferable. A good cellar is one that can be kept dark, dry, well ventilated and at an even temperature of about 45 degrees Fahrenheit throughout the winter. If these conditions are not provided, then the cellar may be a dangerous place in which to put the bees. For a small number of colonies a corner of the basement beneath the beekeeper's residence may be partitioned off so as to provide the conditions outlined above.

If wintering in a cellar the bees should be brought in immediately following the last good flight they are likely to get. In most districts this usually occurs early in November. It is better to bring the bees in a little early than it is to leave them exposed to cold stormy weather waiting for a flight they may not get. The bees should be brought in with as little disturbance as possible. Close the hive entrance when taking them in and as soon as they are in open the entrance again. If the cellar is inclined to be a little warm remove the covers from the colonies, replacing them with a porous material such as sacking and leave the hive entrances wide open, but if the cellar is on the cold side leave the hive covers on and reduce the entrances to about two or three inches. If the cellar is well built, and the conditions already outlined can be maintained, the bees will require little or no attention throughout the winter, provided they are young and well fed. It may be necessary, however, to watch them as the weather warms up the following spring and to check as far as possible any restlessness that might occur. Cellar wintered bees should remain in the cellar until willow blossoms are yielding pollen in the spring unless dysentery and restlessness have developed, then they may have to be brought out to save them.

If bees are to be wintered outside place them in their cases during the latter part of September just before the feeding is to be done and pack the cases beneath the colonies and on all four sides. After feeding is finished add the top packing.

The cases may be of a size to hold one or more colonies, but the most economical case is one that will hold four colonies en bloc with no space between the hives. No matter how many colonies the case may hold it must be large enough to allow for at least four inches (more where the winter is very severe) of packing between the walls of the case (bottom and sides) and the colonies, and at least six inches on top with an air space between the top packing and 
the cover of the case. There should be an opening in the sides or ends of the case directly opposite each colony entrance so that the bees may take a flight whenever weather conditions permit. It is also advisable to have at least a one-inch hole at each end and near the top of the case to allow for a circulation of the air above the packing to carry off any moisture that may accumulate there. The cases should be constructed so as to keep the packing material dry from outside moisture; wet packing loses its insulating value. Planer shavings, dry leaves, cut straw or any other well-known insulating material can be used as packing. A good windbreak is an important part of winter protection, therefore, it is advisable to have windbreaks on at least three sides of the apiary. If natural protection is absent a slatted wooden fence about seven feet high should be provided.

Outdoor wintered bees should be left in their cases until the latter interfere with the spring manipulation of the colonies. It is the early protection in the fall and the late protection in spring that makes outdoor wintering so attractive. 
Digitized by the Internet Archive in 2012 with funding from

Agriculture and Agri-Food Canada - Agriculture et Agroalimentaire Canada 
